\title{
BMJ Open Impact of night shifts on sleeping patterns, psychosocial and physical well-being among healthcare professionals: a cross-sectional study in a tertiary hospital in Saudi Arabia
}

Sultan Qanash, ${ }^{1,2,3}$ Hassan Alwafi (1) , ${ }^{4}$ Shaima Barasheed, ${ }^{5}$ Shahad Bashnaini, ${ }^{5}$ Rahaf Andergiri, ${ }^{5}$ Loujain Yaghmour, ${ }^{5}$ Weam Murad, ${ }^{1}$ Mohammed Shabrawishi, ${ }^{6}$ Abdallah Y Naser (D) ,7 Basim Alsywid ${ }^{8,9}$

To cite: Qanash S, Alwafi H, Barasheed S, et al. Impact of night shifts on sleeping patterns, psychosocial and physical well-being among healthcare professionals: a cross-sectional study in a tertiary hospital in Saudi Arabia. BMJ Open 2021;11:e046036. doi:10.1136/ bmjopen-2020-046036

- Prepublication history for this paper is available online. To view these files, please visit the journal online (http://dx.doi. org/10.1136/bmjopen-2020046036).

Received 20 0ctober 2020 Accepted 28 July 2021

Check for updates

(c) Author(s) (or their employer(s)) 2021. Re-use permitted under CC BY-NC. No commercial re-use. See rights and permissions. Published by BMJ.

For numbered affiliations see end of article.

Correspondence to

Dr Sultan Qanash;

qanashsu@ngha.med.sa

\section{ABSTRACT}

Background Shift work and night shifts are very common in healthcare organisations worldwide. However, healthcare professionals doing shift work and night shifts are exposed to several stressors with psychological, social, physical and sleeping consequences. This study aimed to evaluate the effect of night shifts on the psychosocial, physical well-being and sleeping patterns of healthcare professionals in Saudi Arabia.

Methods We conducted an observational crosssectional study from July to September 2019 at King Abdulaziz Medical City, Jeddah, Saudi Arabia. Convenience sampling technique was used to recruit healthcare providers to participate in the study. The outcomes measured included the effect of working hours of healthcare workers on psychosocial and physical health, substance use, and sleep quality and patterns. Pearson's $\chi^{2}$ test was used to compare proportions, and Student's t-test/Analysis of variance (ANOVA) was used to examine the mean differences among different demographic groups.

Results A total of 352 healthcare providers were involved in the study, of whom only 272 were night shift workers. The mean level of job satisfaction was higher among day shift workers than night shift workers: the mean scores were $3.82(\mathrm{SD}=0.93)$ and 3.48 (SD=1.04), respectively, $p=0.007$. Moreover, social life was more adversely affected among night shift workers compared with day shift workers: 3.95 $(S D=1.11)$ and 3.61 (SD=1.25), respectively, $p<0.030$. Likewise, family life was more adversely affected among night shift workers than day shift workers, with a mean of $3.92(S D=1.10)$ and $3.50(S D=1.21)$, respectively, $p<0.006$. Around $71 \%$ of night shift workers reported having poor-quality sleep compared with $50 \%$ of day shift workers ( $p=0.001)$.

Conclusion Quality of life is poor among night shift workers than day shift workers, particularly concerning sleep and social and physical outcomes. Further research is needed to investigate factors associated with the quality of sleep and the psychosocial and physical

\section{Strengths and limitations of this study}

- This study included all healthcare providers from different specialities in a large tertiary hospital for adult healthcare.

- The study design itself, a cross-sectional survey design, limited our ability to identify causality between study variables.

- The lack of comparison with other samples collected in different hospitals could limit the generalisability of our results.

well-being of healthcare professionals working night shifts.

\section{INTRODUCTION}

Many essential professions are required to work continuously and to provide highquality service to their clients around the clock, but this is limited by individual, financial and organisational factors. ${ }^{12}$ It is estimated that $>20$ million Americans and Europeans work night shifts, and healthcare workers represent a large proportion of this population. To overcome the limitations, these services arrange their work schedules based on shift work that may last up to 24 hours. ${ }^{3}$ Several models have been adopted and studied to observe the effects of the duration of shifts, day and night assignments, and the cumulative working hours per week on employees' physical and psychological health. ${ }^{4-7}$ Night shift healthcare workers had higher error rates and worse patient safety outcomes compared with their colleagues working day hours; this was partially related to circadian rhythm derangement and sleeprelated disorders. ${ }^{8}{ }^{9}$ Sleep deprivation itself 
has been linked to cardiovascular morbidity, metabolic syndrome, psychosocial disorders and an overall decline in well-being. ${ }^{10-13}$ Furthermore, self-reported well-being has been associated with improved quality of sleep and productivity. ${ }^{14}$

In recent years, there have been ongoing research and institutional quality improvement projects to further characterise deficiencies and improve the healthcare work environment. However, in the Middle East, few studies have evaluated the effects of shift work on the sleep quality of healthcare professionals or the associated physical and psychosocial well-being of night-time workers. Therefore, the objective of our study was to evaluate the effects of night shift work on the physical health, psychosocial wellbeing and the quality of sleep of healthcare workers.

\section{METHODS}

\section{Study setting}

The study was conducted at King Abdul-Aziz Medical City, Jeddah, Saudi Arabia, after obtaining approval from the Institutional Review Boards (SP18.470.J). The study was conducted between July and September 2019. All adult healthcare providers in King Abdul-Aziz Medical City, including nurses, physicians and applied healthcare professionals were included in the study. Patients and hospital administrators were excluded from the study.

\section{Study design}

This was an observational cross-sectional study where adult healthcare providers were invited to participate in completing a self-administrated questionnaire.

\section{Participants' recruitment}

Healthcare providers, including nurses, physicians and applied healthcare professionals (including all healthcare workers that work in the hospital except for doctors and nurses), were approached and requested to participate in the study. All study participants were informed that completing and returning the questionnaire would be considered written consent and agreement of participation. All participants were assured that the questionnaire was anonymous and that they would not be asked for their name anywhere on the questionnaire and their information would not be used for any purpose other than this research. Finally, they were notified that participation was voluntary.

\section{Sampling strategy}

The sampling technique was a non-probability convenience sampling technique. The data were collected through a self-administered questionnaire (data collection tool in which written questions are presented that are to be answered by the respondents in written form). This sampling technique involves recruiting participants who meet the inclusion criteria of the study and who are easily accessible based on geographical proximity, availability at a given time or willingness to take part in the study. This approach enabled the researcher to gain the participation of a large number of the targeted population. Healthcare providers were invited, and those who were willing to participate in the study formed the study population.

\section{The questionnaire tool}

The questionnaire was written in English and the survey underwent a validation process of face validity and reliability. The survey consisted of four main sections. The first section concerned demographic characteristics, including age, gender, marital status, job title and length of working hours. At the end of this section, we divided the responders into two subgroups (night shift and day shift workers). The second section concerned the psychosocial consequences of working hours through specific questions about job satisfaction, safety of performance, desire to leave the job, the adverse effect on social and family life, and contact with family during an emergency. Participants response for this section was evaluated using 5-point Likert scale that ranged between 1 and 5 , where 1 means strongly disagree and 5 strongly agree, the higher the agreement degree (higher score) the more the participants is being affected by the work shift. The third section concerned reported physical symptoms and substance use. The definition of substance use included the consumption of coffee, tea, energy drinks or stimulant pills (caffeine pills or any other known stimulant pills), regardless of the frequency and the dose. The last section concerned the reported effect of working hours on sleep quality and patterns. The third and fourth sections responses were evaluated using yes/no and multiple choice question format.

\section{Pretesting of the questionnaire tool}

The final draft of the questionnaire tool was checked for clarity and comprehensibility by healthcare professionals from different specialties and they confirmed that, based on their experience, it would be easily understood.

A pilot study using the final draft of the questionnaire tool was then conducted on 20 healthcare professionals in the same healthcare centre at which we conducted the full study. Those participants met the inclusion criteria for the study. They were asked about the clarity and comprehensibility of the questionnaire and whether any of the questions were difficult to understand. In addition, they were asked if any of the questions were considered unacceptable or offensive. Healthcare professionals confirmed that the questionnaire was considered easy to understand and complete.

\section{Reliability and consistency of the questionnaire tool}

The Cronbach's $\alpha$ measure for the five factors to assess psychological consequences was 0.7 . This shows that the psychological consequences scale was of acceptable quality. 


\begin{tabular}{|c|c|c|c|}
\hline Variables & $\begin{array}{l}\text { Total } \\
(\mathrm{n}=352)\end{array}$ & $\begin{array}{l}\text { Male } \\
(n=174)\end{array}$ & $\begin{array}{l}\text { Female } \\
(n=178)\end{array}$ \\
\hline \multicolumn{4}{|l|}{ Demographics } \\
\hline Age (years) & $\begin{array}{l}30.6 \\
(\mathrm{SD}=7.52)\end{array}$ & $\begin{array}{l}30.6 \text { years } \\
(\mathrm{SD}=7.01)\end{array}$ & $\begin{array}{l}30.6 \\
(\mathrm{SD}=8.04)\end{array}$ \\
\hline \multicolumn{4}{|l|}{ Social life, no. (\%) } \\
\hline Single & $180(51.1)$ & $80(46.0)$ & $100(56.1)$ \\
\hline Married & $172(48.9)$ & $94(54.0)$ & $78(43.8)$ \\
\hline \multicolumn{4}{|c|}{ Health professionals, no. (\%) } \\
\hline Physician & $131(37.2)$ & $93(53.4)$ & $38(21.3)$ \\
\hline Nurse & $134(38.1)$ & $27(15.5)$ & $107(60.1)$ \\
\hline Applied healthcare & $87(24.7)$ & $54(31.0)$ & $33(18.5)$ \\
\hline \multicolumn{4}{|c|}{ Modality of work, no. (\%) } \\
\hline Day shift work & $80(22.7)$ & $37(21.2)$ & $43(24.2)$ \\
\hline Night shift work & $272(77.3)$ & $137(78,8)$ & $135(75.8)$ \\
\hline \multicolumn{4}{|c|}{ Period of night shift work, no. (\%) } \\
\hline$<2$ years & $77(21.8)$ & $48(27.6)$ & $29(16.2)$ \\
\hline $2-5$ years & $71(20.1)$ & $43(24.7)$ & $28(15.7)$ \\
\hline$>5$ years & $126(35.8)$ & $48(27.6)$ & $78(43.8)$ \\
\hline \multicolumn{4}{|c|}{ Length of working hours, no. (\%) } \\
\hline 8 hours & $94(26.7)$ & $50(28.7)$ & $44(24.7)$ \\
\hline 12 hours & $188(53.4)$ & $77(44.2)$ & $111(31.5)$ \\
\hline 24 hours & $38(10.7)$ & $29(16.6)$ & $9(5.0)$ \\
\hline Others & $30(8.5)$ & $17(9.7)$ & $13(7.3)$ \\
\hline \multicolumn{4}{|l|}{ Sleeping hours, no. (\%) } \\
\hline$<6$ hours & $149(42.3)$ & $78(44.8)$ & $71(40.0)$ \\
\hline $6-8$ hours & $183(52.0)$ & $89(51.1)$ & $94(52.8)$ \\
\hline$>8$ hours & $16(4.5)$ & $6(3.4)$ & $10(5.6)$ \\
\hline
\end{tabular}

\section{Sample size}

The target population size was 3000 participants and the sample size that needed to be collected was 345 participants to obtain $95 \%$ confidence with a $5 \%$ margin of error.

\section{Statistical analysis}

Descriptive statistics were reported as mean $( \pm \mathrm{SD})$ for normally distributed quantitative variables. To calculate the frequencies of each variable, Pearson's $\chi^{2}$ test was used to compare proportions and the Student's t-test was used to examine the differences between the mean scores. ANOVA test was used to compare the mean scores (mean score which reflects the psychosocial consequences of working hours through specific questions about job satisfaction, safety of performance, desire to leave the job, the adverse effect on social and family life and contact with family during an emergency) between different and within each demographic groups. A p-value of $<0.5$ was considered statistically significant, with a CI of $95 \%$. All data were analysed using SPSS, V.24 for Windows.

Table 2 Physical symptoms and psychological health perception among our healthcare professionals divided by modality of work

\begin{tabular}{llll}
\hline $\begin{array}{l}\text { Questionnaire } \\
\text { items, } \mathbf{n}(\%)\end{array}$ & $\begin{array}{l}\text { Night shift } \\
\text { workers, } \mathbf{n}(\%)\end{array}$ & $\begin{array}{l}\text { Day shift } \\
\text { workers, } \mathbf{n}(\%)\end{array}$ & $\begin{array}{l}\text { P value, } \\
\text { Pearson }\end{array}$ \\
\hline Headache & $138(51.3 \%)$ & $47(58.8 \%)$ & $\begin{array}{l}\mathrm{p}=0.0171, \\
1.374\end{array}$ \\
\hline Fatigue & $181(67.3 \%)$ & $55(68.8 \%)$ & $\begin{array}{l}\mathrm{p}=0.494, \\
0.060\end{array}$ \\
Depression & $97(36.0 \%)$ & $28(35.0 \%)$ & $\begin{array}{l}\mathrm{p}=0.862, \\
0.030\end{array}$ \\
Mood irritability & $159(59.1 \%)$ & $42(52.2 \%)$ & $\begin{array}{l}\mathrm{p}=0.294, \\
1.102\end{array}$ \\
$\begin{array}{l}\text { Psychological } \\
\text { health }\end{array}$ & $85(31.8 \%)$ & $16(20.0 \%)$ & $\begin{array}{l}\mathrm{p}=0.026, \\
4.034 \\
\mathrm{p}=0.119, \\
1.780\end{array}$ \\
$\begin{array}{l}\text { Cardiovascular } \\
\text { health }\end{array}$ & $39(14.6 \%)$ & $7(8.8 \%)$ & $\begin{array}{l}\mathrm{p}=0.294, \\
0.462\end{array}$ \\
$\begin{array}{l}\text { Gastrointestinal } \\
\text { health }\end{array}$ & $60(22.5 \%)$ & $15(18.8 \%)$ & \\
\hline
\end{tabular}

$n$, frequency.

\section{Patient and public involvement}

It was not appropriate or possible to involve patients or the public in the design, implementing, reporting or dissemination plans of our research.

\section{RESULTS}

\section{Study participants' characteristics}

In table 1, the baseline participants' characteristics are reported. A total of 352 healthcare professionals participated in the study and were included in the final analysis. The mean age of our sample was 30.6 years $(\mathrm{SD}=7.52)$ and half of the sample consisted of women (50.6\%). Physicians and nurses represented three-quarters of the study participants. Most of them reported that their scheduled work included night shifts $(77.8 \%)$. About half of our sample reported working in their current field for $>5$ years whereas only $28.1 \%$ had worked for $<2$ years.

\section{Physical symptoms and psychological health perception}

In table 2, physical symptoms and psychological health perception among our healthcare professionals are reported. Our results showed that only the perception of psychological health and sleep quality and quantity were statistically significantly different between night and day shift workers. There was a statistically significant difference in the mean level of job satisfaction. The mean level of job satisfaction among night shift workers was $3.48(\mathrm{SD}=1.04)$, while the mean for day shift workers was $3.82(\mathrm{SD}=0.93), \mathrm{p}=0.007$. However, there was no statistical difference in the mean level of safety of performance; mean for night shift workers was $3.59(\mathrm{SD}=1.2)$ and mean for day shift workers was 3.63 $(\mathrm{SD}=1.07), \mathrm{p}<0.761$. Less than half of the participants would prefer to leave their job (37.9\%), most of whom 
Table 3 The psychosocial consequences of working hours among our healthcare professionals divided by modality of work

\begin{tabular}{|c|c|c|c|}
\hline $\begin{array}{l}\text { Questionnaire } \\
\text { items, } \\
\text { mean } \pm \text { SD }\end{array}$ & $\begin{array}{l}\text { Night shift } \\
\text { workers }\end{array}$ & $\begin{array}{l}\text { Day shift } \\
\text { workers }\end{array}$ & $\begin{array}{l}P \text { value, } \\
\text { t-test }\end{array}$ \\
\hline $\begin{array}{l}\text { Level of job } \\
\text { satisfaction }\end{array}$ & $3.48(\mathrm{SD}=1.04)$ & $3.82(\mathrm{SD}=0.93)$ & $\begin{array}{l}p=0.007 \\
2.578\end{array}$ \\
\hline $\begin{array}{l}\text { Level of safety } \\
\text { performance }\end{array}$ & $3.59(\mathrm{SD}=1.2)$ & $3.63(\mathrm{SD}=1.07)$ & $\begin{array}{l}p<0.761 \\
0.286\end{array}$ \\
\hline $\begin{array}{l}\text { Adverse effect } \\
\text { of working hours } \\
\text { on social life }\end{array}$ & $3.95(\mathrm{SD}=1.11)$ & $3.61(\mathrm{SD}=1.25)$ & $\begin{array}{l}p<0.030 \\
-2.337\end{array}$ \\
\hline $\begin{array}{l}\text { Adverse effect } \\
\text { of working hours } \\
\text { on family life }\end{array}$ & $3.92(\mathrm{SD}=1.10)$ & $3.50(\mathrm{SD}=1.21)$ & $\begin{array}{l}p<0.006 \\
-2.925\end{array}$ \\
\hline
\end{tabular}

were night shift workers (83\%). Social and family life are significantly affected by night shift work compared with day shift work. The mean of the adverse effect of working hours on social life for night shift workers was $3.95(\mathrm{SD}=1.11)$, and for day shift workers was 3.61 $(\mathrm{SD}=1.25)$, with $\mathrm{p}<0.030$. Furthermore, family lives are more adversely affected for night shift workers than day shift workers, with a mean of $3.92(\mathrm{SD}=1.10)$ and 3.50 $(\mathrm{SD}=1.21)$, respectively, $\mathrm{p}<0.006$. However, working hours do not affect workers' responsibility towards their family during an emergency, $\mathrm{p}<0.757$ (see table 3 ).

\section{Substance use}

Around $78.3 \%$ of the participants reported that they used caffeine, while $23.2 \%$ reported that they smoked to cope with their work. Use of stimulant pills was the lowest at $3.8 \%$ (table 4 ).

\section{Quality and pattern of sleep}

There is a significant difference between night shift and day shift healthcare. Around $71 \%$ of night shift workers reported having poor sleep quality compared with $50 \%$ of day shift workers $(p=0.001)$. Night shift workers reported having more problem in falling asleep (52.2\%) and staying asleep $(53.0 \%)$ compared with day shift workers $(\mathrm{p}=0.014)$ and $(\mathrm{p}=0.002)$, respectively. In table 5, the self-reported quality and pattern of sleep among healthcare professionals divided by their type of shift work are

\begin{tabular}{|c|c|c|c|}
\hline $\begin{array}{l}\text { Substance, n } \\
(\%)\end{array}$ & $\begin{array}{l}\text { Night shift } \\
\text { workers }\end{array}$ & $\begin{array}{l}\text { Day shift } \\
\text { workers }\end{array}$ & $\begin{array}{l}\text { P value, } \\
\text { Pearson } \chi^{2}\end{array}$ \\
\hline Caffeine & 210 (78.9\%) & 60 (75.9\%) & $\begin{array}{l}p=0.335 \\
0.331\end{array}$ \\
\hline Smoking & 68 (25.6\%) & 12 (15.2\%) & $\begin{array}{l}p=0.035, \\
3.687\end{array}$ \\
\hline Stimulants pills & $12(4.5 \%)$ & $1(1.3 \%)$ & $\begin{array}{l}p=0.160 \\
1.773\end{array}$ \\
\hline
\end{tabular}

$\mathrm{n}$, frequency
Table 5 Quality and pattern of sleep among our healthcare professionals divided by the modality of work

\begin{tabular}{lcll}
\hline $\begin{array}{l}\text { Questionnaire } \\
\text { items, } \mathbf{n}(\%)\end{array}$ & $\begin{array}{l}\text { Night shift } \\
\text { workers }\end{array}$ & $\begin{array}{l}\text { Day shift } \\
\text { workers }\end{array}$ & $\begin{array}{l}\text { P value, } \\
\text { Pearson } \chi^{2}\end{array}$ \\
\hline Poor sleep quality & $189(70.8 \%)$ & $40(50.0 \%)$ & $\begin{array}{l}\mathrm{p}=0.001, \\
4.782\end{array}$ \\
Not falling asleep & $140(52.2 \%)$ & $30(37.5 \%)$ & $\begin{array}{l}\mathrm{p}=0.014, \\
5.356\end{array}$ \\
Not staying asleep & $142(53.0 \%)$ & $27(33.8 \%)$ & $\begin{array}{l}\mathrm{p}=0.002, \\
9.125\end{array}$ \\
\hline Sleeping hours, N (\%) & & \\
\hline > h hours & $124(46.1 \%)$ & $26(32.5 \%)$ & $\begin{array}{l}\mathrm{p}=0.037, \\
6.62\end{array}$ \\
6-8hours & $131(48.7 \%)$ & $52(65 \%)$ & \\
$<6$ hours & $14(5.2 \%)$ & $2(2.5 \%)$ & \\
\hline
\end{tabular}

$n$, frequency.

reported. In terms of average sleeping hours per night, night shift works reported fewer sleep hours compared with day shift workers.

Healthcare professional specialty in relation to physical symptoms, psychological health perception, substance use, and quality and pattern of sleep

In the night shift group, there was a statistically significant difference between specialties in the proportion of healthcare professionals who suffered from headaches, in which nurses presented a statistically significant higher proportion compared with physicians and applied healthcare professionals $(\mathrm{p}=0.009)$. However, there was no statistically significant difference between healthcare professionals in the day shift group in terms of physical symptoms.

Concerning psychological consequences, in the night shift group, using ANOVA test we found that there was a statistically significant difference in the mean job satisfaction score between healthcare professionals, in which physicians and applied healthcare professionals showed a statistically significant higher mean score compared with nurses $(\mathrm{p}=0.039)$. In the day shift group, there was a statistically significant difference in the mean score related to adverse effects of working hours on social life of healthcare professionals, in which physicians and applied healthcare professionals showed a statistically significant higher mean score compared with nurses $(\mathrm{p}=0.017)$.

There was no statistically significant difference in terms of stimulant substance use either in the night shift group or day shift group between healthcare professionals from different specialities. However, quality and pattern of sleep differed statistically in the night shift group between healthcare professionals from different specialities, in which a statistically significant higher proportion of nurses reported poor quality of sleep (not falling asleep and staying asleep, $\mathrm{p}=0.000$ and $\mathrm{p}=0.022$, respectively). In addition, there was a statistically significant difference in the sleeping hours between the two groups (refer to table 6). 


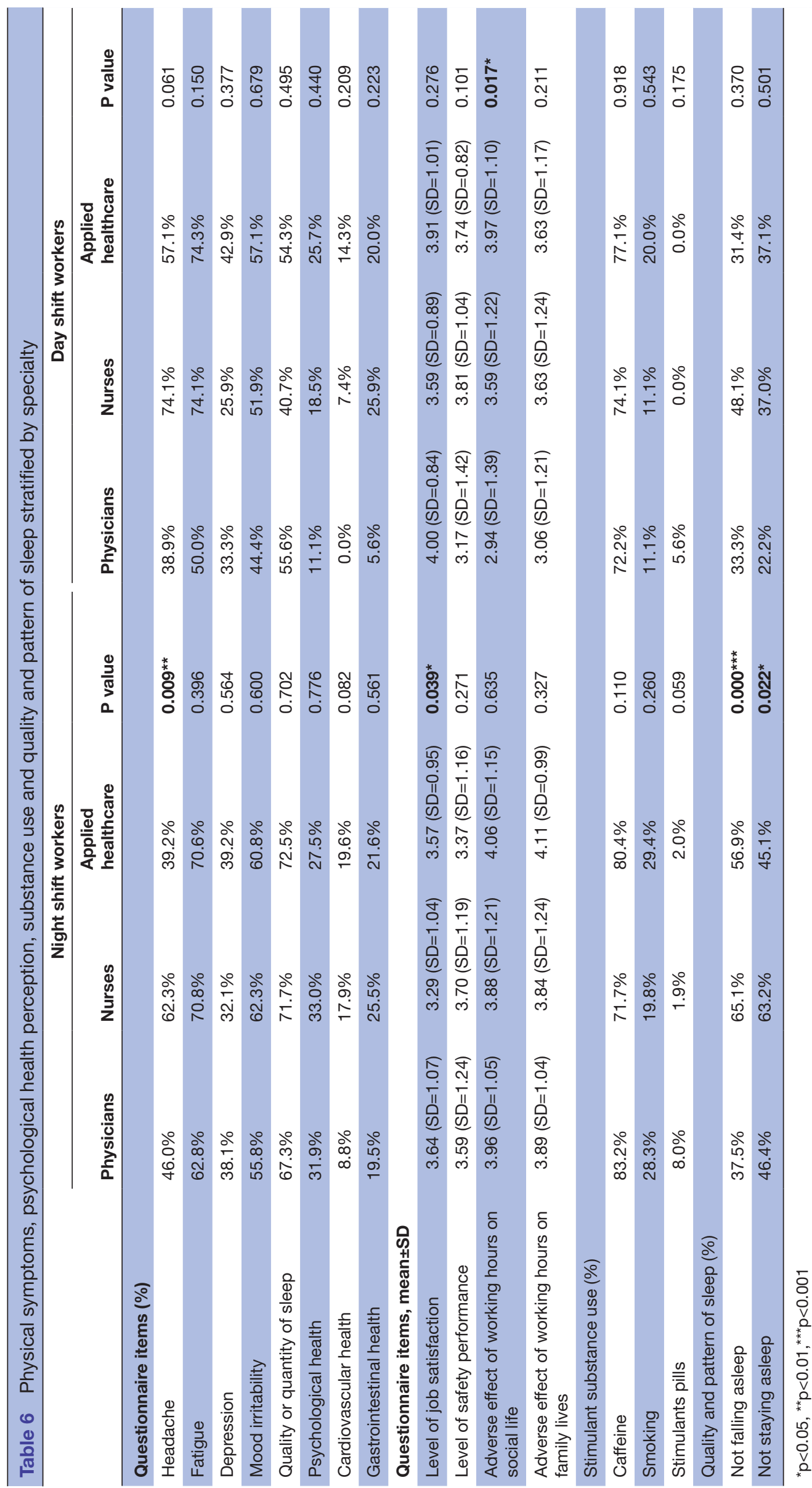




\section{DISCUSSION}

In this cross-sectional study, we found that night shift workers were more likely to have sleep disturbances, particularly in terms of initiating sleep, staying asleep and duration of sleep compared with day shift workers. Additionally, self-reported better sleep quality showed statistical significance favouring day shift workers.

Our cohort study was in concordance with a previously reported study in Saudi Arabia where it was found that shift healthcare workers had worse sleep quality based on the Pittsburgh Sleep Index score compared with their colleagues working day schedules. ${ }^{15}$ The high prevalence of poor sleep quality seems to persist to later age among night shift workers, even after retirement, ${ }^{16}$ and the long-lasting effects of sleep disturbances have detrimental consequences on several aspects of health, precipitating the need for intervention. ${ }^{9}$

Healthcare professionals tend to cope with sleep disorders and daytime fatigue symptoms by consuming caffeinated products and increasing the frequency of interrupted naps, which may further aggravate circadian rhythm disturbances and lead to physical and psychosocial deterioration. ${ }^{17}$ Most of the healthcare workers in our institute reported that they consume coffee but seldom use stimulant drugs. The circadian rhythm cycle is affected by endogenous biological factors and light-dark cycle effects as phase shifts, change and resetting are regulated by photic stimulation, core body temperature and other physiological myocardial and neuronal activities. ${ }^{18} 19$ Permanent night shift workers have a greater ability to accommodate disrupted sleep and changing schedules, and they have reported having better sleep quality compared with rotating shift workers. ${ }^{20}$ These findings may suggest several interventions to improve sleep hygiene by introducing fixed schedules or slower changes to shift rotations to minimise biological clock disturbances.

Night shift work can cause health and social problems, such as psychophysiological problems (depression and anxiety), cardiovascular problems (hypertension and heart disease) and a lack of family communication. ${ }^{21} 22$ In our analysis, headaches and fatigue were the most commonly reported symptoms, which was similar to previous studies. ${ }^{23}{ }^{24}$ However, the occurrence of chronic adverse effects depends on multiple factors such as age, duration of exposure or inappropriate behaviours. Our cohort was young and healthy, which may limit cardiovascular, metabolic, and gastrointestinal symptoms, or other comorbidities. This is supported by Ramin and colleagues ${ }^{6}$ who suggested that adverse chronic diseases occur less frequently in younger shift workers. The duration of exposure to night shift work is a significant factor and is linked to a higher risk of cardiovascular morbidity, ${ }^{25} 26$ metabolic syndrome and obesity ${ }^{13}$ and gastrointestinal nutritional deficiencies. $^{27} 28$ Our cohort of night shift workers had a higher smoking rate compared with their colleagues, which has also been observed anecdotally among shift workers and which may increase the risk cardiovascular disease. ${ }^{29}$

Although shift work has unfavourable effects on a person's psychological health, there is little evidence linking rotating shifts or weekend shifts to psychological breakdown. ${ }^{21} 3031$
Our study did not show a significant difference between night shift workers and day shift workers. However, a recent systemic review that included prospective longitudinal studies revealed that night shift workers were at risk of developing depression and anxiety spectrum disorders; mothers and new parents were considered to be at highest risk. ${ }^{23} 29$

The negative association between job satisfaction and night shift work has been observed in the healthcare setting: night workers request more sick days and report frequent use of over-the-counter medications. ${ }^{32}$ This is similar to what was reported among our cohort where self-reported job satisfaction was lower among night workers compared with day shift workers. Although we did not observe significant concern regarding safety outcomes, it has previously been found that resident physicians working the traditional 24-hour on-call shift are more prone to fatigue-related occupational hazards and motor vehicle accidents. ${ }^{33}$

Understandably, night shift work might affect family and social life substantially. ${ }^{34}$ This could be due to the inability to attend family and social gatherings due to working hours and the effect of the day after. ${ }^{35}$ In our study, self-reported family and social life satisfaction were lower among night shift workers compared with day shift workers, regardless of gender or marital status. This is in contrast to what was reported by Japanese nurses, who found that night shift work did not affect family conflicts or relationships, but rather that shift flexibility and child care had a significant impact on maintaining healthy family relationships. ${ }^{36}$

Work shift impact on healthcare professionals is not the same. This is highly influenced by their specialty, work load and ultimately the need and frequency of them being involved in night shifts.

A previous systematic review has reported that there is more risk on women compared with men in relation to work shift as in most hospitals the majority of caregivers and nurses are women. ${ }^{37}$

Recommended compensatory behaviour to minimise any expected negative impacts associated with shift work includes napping, practicing physical exercises, forward rotation (from mornings to afternoons to nights), social support and leader support. ${ }^{38}$

\section{Limitations}

The study design itself, a cross-sectional survey design, limited our ability to identify causality between study variables. A further limitation of this study was the lack of comparison with other samples collected in different hospitals, which may affect the generalisability of the study. We suggest that future studies be performed at a multicentre or at a national level, which might result in better generalisability.

\section{CONCLUSION}

In conclusion, our results revealed that night shift work was more likely to affect sleep patterns and quality, and that it affects night shift workers' psychological health and overall well-being. This concern ought to alert health organisations to consider the health and safety of their healthcare workers. 
Author affiliations

${ }^{1}$ Medicine Department, Minstry of the National Guard, Health Affairs, Jeddah, Saudi Arabia

${ }^{2}$ King Abdullah International Medical Research Center, Jeddah, Saudi Arabia

${ }^{3}$ King Saud Bin Abdulaziz University for Health Sciences, Jeddah, Saudi Arabia

${ }^{4}$ Faculty of Medicine, Umm Alqura University, Mecca, Saudi Arabia

${ }^{5}$ Department of Respiratory Therapy, College of Applied Medical Sciences, King

Saud Bin Abdulaziz University for Health Sciences, Jeddah, Saudi Arabia

${ }^{6}$ Department of Respiratory Medicine, Al Noor Specialist Hospital, Mecca, Saudi

Arabia

${ }^{7}$ Department of Applied Pharmaceutical Sciences and Clinical Pharmacy, Isra University Faculty of Pharmacy, Amman, Jordan

${ }^{8}$ College of Medicine, King Saud Bin Abdulaziz University for Health Sciences, King Abdulaziz Medical City, Jeddah, Saudi Arabia

${ }^{9}$ Research and Development Department, Planning and Organizational Excellence Administration, Saudi Commission for Health Specialties, Riyadh, Saudi Arabia

\section{Twitter Basim Alsywid @drbasim}

Contributors SQ: conceptualisation; SBar, SBas, RA, LY and WM: data curation; $B A, A Y N$ and HA: formal analysis; $S Q$ and HA: investigation; SQ, AYN and BA: methodology; SQ: project administration; SQ, SBar, SBas, RA, LY, MS and WM: resources; SQ: supervision; SQ and HA: validation; SQ, SBar, SBas, RA, LY, MS, WM and $\mathrm{HA}$ : writing of the original draft; all authors contributed to the writing, review and editing.

Funding The authors have not declared a specific grant for this research from any funding agency in the public, commercial or not-for-profit sectors.

Competing interests None declared.

Patient and public involvement Patients and/or the public were not involved in the design, or conduct, or reporting, or dissemination plans of this research.

Patient consent for publication Not required.

Ethics approval The study was conducted at King Abdul-Aziz Medical City, Jeddah, Saudi Arabia, after obtaining approval from the Institutional Review Boards (SP18.470.J).

Provenance and peer review Not commissioned; externally peer reviewed.

Data availability statement № data are available.

Open access This is an open access article distributed in accordance with the Creative Commons Attribution Non Commercial (CC BY-NC 4.0) license, which permits others to distribute, remix, adapt, build upon this work non-commercially, and license their derivative works on different terms, provided the original work is properly cited, appropriate credit is given, any changes made indicated, and the use is non-commercial. See: http://creativecommons.org/licenses/by-nc/4.0/.

\section{ORCID iDs}

Hassan Alwafi http://orcid.org/0000-0003-4735-0262

Abdallah Y Naser http://orcid.org/0000-0001-8440-7446

\section{REFERENCES}

1 Perrucci R, MacDermid S, King E, et al. The significance of shift work: current status and future directions. J Fam Econ Issues 2007;28:600-17.

2 Costa G. Shift work and health: current problems and preventive actions. Saf Health Work 2010;1:112-23.

3 Harrington JM. Health effects of shift work and extended hours of work. Occup Environ Med 2001;58:68-72.

4 Joyce K, Pabayo R, Critchley JA, et al. Flexible working conditions and their effects on employee health and wellbeing. Cochrane Database Syst Rev 2010;2010:Cd008009.

5 Ferri P, Guadi M, Marcheselli L, et al. The impact of shift work on the psychological and physical health of nurses in a general Hospital: a comparison between rotating night shifts and day shifts. Risk Manag Healthc Policy 2016;9:203-11.

6 Ramin C, Devore EE, Wang W, et al. Night shift work at specific age ranges and chronic disease risk factors. Occup Environ Med 2015;72:100-7.

7 Korompeli A, Muurlink O, Tzavara C, et al. Influence of shiftwork on Greek nursing personnel. Saf Health Work 2014;5:73-9.
8 Estabrooks CA, Cummings GG, Olivo SA, et al. Effects of shift length on quality of patient care and health provider outcomes: systematic review. Qual Saf Health Care 2009;18:181-8.

9 Kecklund G, Axelsson J. Health consequences of shift work and insufficient sleep. BMJ 2016;355:i5210.

10 Wyse CA, Celis Morales CA, Graham N, et al. Adverse metabolic and mental health outcomes associated with shiftwork in a populationbased study of 277,168 workers in UK biobank<sup/\&gt. Ann Med 2017;49:411-20.

11 Gallicchio L, Kalesan B. Sleep duration and mortality: a systematic review and meta-analysis. J Sleep Res 2009;18:148-58.

12 McNeil J, Doucet Éric, Chaput J-P. Inadequate sleep as a contributor to obesity and type 2 diabetes. Can J Diabetes 2013;37:103-8.

13 Medic G, Wille M, Hemels ME. Short- and long-term health consequences of sleep disruption. Nat Sci Sleep 2017;9:151-61.

14 Steptoe A, Wardle J, skills L. Life skills, wealth, health, and wellbeing in later life. Proc Natl Acad Sci U S A 2017;114:4354-9.

15 Alshahrani SM, Baqays AA, Alenazi AA, et al. Impact of shift work on sleep and daytime performance among health care professionals. Saudi Med J 2017;38:846-51.

16 Monk TH, Buysse DJ, Billy BD, et al. Shiftworkers report worse sleep than day workers, even in retirement. J Sleep Res 2013;22:201-8.

17 Schlafer O, Wenzel V, Högl B. [Sleep disorders among physicians on shift work]. Anaesthesist 2014;63:844-51.

18 Duffy JF, Czeisler CA. Effect of light on human circadian physiology. Sleep Med Clin 2009;4:165-77.

19 Reppert SM, Weaver DR. Coordination of circadian timing in mammals. Nature 2002;418:935-41.

20 Pilcher JJ, Lambert BJ, Huffcutt Al. Differential effects of permanent and rotating shifts on self-report sleep length: a meta-analytic review. Sleep 2000;23:1-9.

21 Camerino D, Sandri M, Sartori S, et al. Shiftwork, work-family conflict among Italian nurses, and prevention efficacy. Chronobiol Int 2010;27:1105-23.

22 Yildirim D, Aycan Z. Nurses' work demands and work-family conflict: a questionnaire survey. Int J Nurs Stud 2008;45:1366-78.

23 Anbazhagan S, Ramesh N, Nisha C, et al. Shift work disorder and related health problems among nurses working in a tertiary care Hospital, Bangalore, South India. Indian J Occup Environ Med 2016;20:35-8.

24 Geiger-Brown J, Rogers VE, Trinkoff AM, et al. Sleep, sleepiness, fatigue, and performance of 12-hour-shift nurses. Chronobiol Int 2012;29:211-9.

25 Kawachi I, Colditz GA, Stampfer MJ, et al. Prospective study of shift work and risk of coronary heart disease in women. Circulation 1995;92:3178-82.

26 Pimenta AM, Kac G, Souza RRCE, et al. Night-Shift work and cardiovascular risk among employees of a public university. Rev Assoc Med Bras 2012;58:168-77.

27 Lennernäs M, Hambraeus L, Akerstedt T. Shift related dietary intake in day and shift workers. Appetite 1995;25:253-66.

28 Morikawa Y, Miura K, Sasaki S, et al. Evaluation of the effects of shift work on nutrient intake: a cross-sectional study. J Occup Health 2008;50:270-8.

29 van Amelsvoort LGPM, Jansen NWH, Kant I. Smoking among shift workers: more than a confounding factor. Chronobiol Int 2006;23:1105-13.

30 Zhao Y, Richardson A, Poyser C, et al. Shift work and mental health: a systematic review and meta-analysis. Int Arch Occup Environ Health 2019;92:763-93.

31 Simunić A, Gregov L. Conflict between work and family roles and satisfaction among nurses in different shift systems in Croatia: a questionnaire survey. Arh Hig Rada Toksikol 2012;63:189-97.

32 Burch JB, Tom J, Zhai Y, et al. Shiftwork impacts and adaptation among health care workers. Occup Med 2009;59:159-66.

33 Lockley SW, Barger LK, Ayas NT, et al. Effects of health care provider work hours and sleep deprivation on safety and performance. Jt Comm J Qual Patient Saf 2007;33:7-18.

34 Skoufi GI, Lialios GA, Papakosta S, et al. Shift work and quality of personal, professional, and family life among health care workers in a rehabilitation center in Greece. Indian J Occup Environ Med 2017;21:115-20.

35 Cheng S-Y, Lin P-C, Chang Y-K, et al. Sleep quality mediates the relationship between work-family conflicts and the self-perceived health status among hospital nurses. J Nurs Manag 2019;27:381-7.

36 Fujimoto T, Kotani S, Suzuki R. Work-family conflict of nurses in Japan. J Clin Nurs 2008;17:3286-95.

37 Poissonnet CM, Véron M. Health effects of work schedules in healthcare professions. J Clin Nurs 2000;9:13-23.

38 Wilson JL. The impact of shift patterns on healthcare professionals. J Nurs Manag 2002;10:211-9. 